\title{
Utilisation of Foundry Sand in Concrete - A Review
}

\author{
D.Sangavi $^{{ }^{*}}$, K. Angu Senthil ${ }^{2}$ \\ ${ }^{1}$ PG Student, Department of Civil Engineering, K.S.Rangasamy College of Technology, Tiruchengode, Tamil Nadu, \\ India. \\ ${ }^{2}$ Assistant Professor, Department of Civil Engineering, K.S.Rangasamy College of Technology, Tiruchengode,Tamil \\ Nadu, India.
}

*Corresponding author E-Mail ID: sangaviuma31@gmail.com,

Doi: https://doi.org/10.34256/irjmtcon51

\begin{abstract}
A Rise in urbanization and industrialization has led to over utilization of natural river sand, which affects environmental sustainability. Nowadays, due to the massive demand of river sand, M-sand has been replaced effectively and being used in the construction industry. Although M-Sand is desirably used, it can lead to more water and cement requirement to achieve the expected workability which in turn increases the cost of construction. Thus as an alternative solution, industrial by-product like waste foundry sand can be used. When sand can no-longer be reused in the foundry, it is known as waste foundry sand. As it is discarded in a landfill, it tends to pose several environmental impacts. In order to reduce the disposal problem, waste foundry sand is reused in engineering applications. In this paper, various strength and durability properties have been studied, and an overview of some of the research works on the utilization of waste foundry sand in concrete were given. Fine aggregate is replaced with different proportions of waste foundry sand $(0-100 \%)$. From the results obtained, the optimum \% replacement of foundry sand is found to be in the range of $20 \%$ to $40 \%$ based on the grade of concrete.
\end{abstract}

Keywords: Concrete, Fine aggregate, industrial by-product, waste foundry sand (WFS), strength properties.

\section{INTRODUCTION}

Concrete is the most widely used heterogeneous construction material consisting of cement, water, river sand and coarse aggregates. High demand for river sand led to the usage of M-Sand which costs around Rs.4000-5000/unit. To reduce the cost of M-Sand, industrial byproducts or solid wastes can be used as an alternative material in producing concrete. Waste foundry sand (WFS) is a by-product from the ferrous and non-ferrous metal casting industries, also referred as spent foundry sand (SFS) or used foundry sand (UFS). It is high quality silica sands, which is easily available, inexpensive and resistance to heat damage and used for moulding and casting operations in foundries. During casting process, moulding sands are repeatedly recycled and reused, until it degrades and becomes unsuitable for further recycling within the foundry. Then, the sand is discarded from the industry and the discarded sand is termed as waste foundry sand. Due to rising disposal costs, land filling is also becoming an environmental problem. In-order to reduce the scarcity of space for land filling, waste foundry sand can be used as an alternative material in concrete. Large volume of waste foundry sand is used in geotechnical applications such as road construction and embankments. 


\section{LITERATURE REVIEWS}

G. Ganesh Prabhu et al studied the effects of foundry sand used as a fine aggregate in concrete production. In this study, fine aggregate is replaced by foundry sand in different proportions $(10 \%, 20 \%, 30 \%, 40 \%$ and 50\%). Various tests like slump cone, compressive strength, split tensile strength, flexural strength and elastic modulus of concrete were performed. The compressive strength of the mixtures at the ages of 7, 28, 90 and 180 days were studied. It was concluded that foundry sand with a replacement beyond $20 \%$ affects the concrete standards. So, replacement \% up to 20 can be effectively used as a fine aggregate for good concrete production.

Gurpreet Singh, and Rafat Siddique investigated the strength properties and abrasion resistance of concrete comprising of waste foundry sand(WFS). The percentage replacement of fine aggregate were $0 \%, 5 \%, 10 \%, 15 \%$ and $20 \%$ of WFS by mass. Properties such as compressive strength, splitting tensile strength, modulus of elasticity and abrasion resistance as depth of wear were examined. The abrasion resistance and strength properties of concrete were enhanced with the replacement of waste foundry sand at all ages. Irrespective of waste foundry sand content and age, abrasion resistance of concrete correlates with its compressive strength, split tensile strength and modulus of elasticity. Author concluded that waste foundry sand up to $15 \%$ can be suitably used for making structural concrete.

Thiruvenkitam Manoharan et al carried out some of the experimental investigations on mechanical, durability and micro-structural properties of concrete. In this experimental study, M20 grade concrete was used. The tests were carried out at the age of 7, 28 and 91 days. The compression strength, splitting tensile strength and modulus of elasticity remains constant up to $20 \%$ replacement and decreased with increase in the percentage of used foundry sand. It is suggested that used foundry sand can be replaced for river sand but the replacement should not exceed $20 \%$.

Rafat siddique et al experimented the concrete mixes in which fine aggregate is partially replaced with used-foundry sand. Resistance to chloride penetration, carbonation, compressive strength and split-tensile strength were evaluated. Mechanical properties of concrete was determined at the age of 28, 90 and 365 days. XRD and SEM techniques were used to investigate micro-structures of control mix and mixes with various replacement $\%$ of foundry sand. The optimum replacement $\%$ of foundry sand is $30 \%$ and it should not exceed $50 \%$. The result showed that, on making good quality concrete and construction materials, foundry sand can be conveniently used.

K. Sarumathi et al studied the mechanical properties of concrete replaced with waste foundry sand(WFS). Different proportions (20\%, 25\% and 30\%) of waste foundry sand are used in the production of concrete. Multiscale modelling is used with the help of the Bazant-Baweja (B3 model) in-order to determine the compressive strength, elastic modulus and Poisson's ratio. M25 and M35 mix proportions were made with 0.4 and 0.5 water-to-cement ratio. From the results obtained, it is recommended to replace $30 \%$ and $20 \%$ of WFS for w/c ratios of $0.4 \& 0.5$.

Gustavo J.L. Coppio et al analysed the effects of Portland cement concrete replaced with waste foundry sand as fine aggregate. The surface electrical resistivity and compressive strength tests were studied and the samples were monitored for 63days. Apart from the reference sample, two types of samples were made. One type of sample (F) was made with $100 \%$ replacement by foundry sand discarded in landfill for a long period of time and the other (G) with $100 \%$ replacement by foundry sand which was discarded recently by the steel industry. From the result obtained, it is concluded that the sample $F$ is not suitable to use in concrete while the sample $G$ may be advised to use for non-structural purposes. Behavior of the electrical resistivity varies based on the characteristics of foundry sand. 
Yucel Guney et al investigated the production of high strength concrete by re-using waste foundry sand. The replacement $\%$ of fine aggregate with waste foundry sand are $0 \%, 5 \%, 10 \%$ and $15 \%$. Various tests were conducted in fresh and hardened concrete. Increase in the ratio of waste foundry sand decreases the slump and the workability of the fresh concrete. Using 5\% of waste foundry sand can be inadequate and the replacement more than $10 \%$ will affect the strength parameters. The obtained results suggest to use the concrete with $10 \%$ of waste foundry sand.

Maria Mavroulidou, and David Lawrence used chemically bound foundry sand using polymeric resin binder to assess the properties of structural concrete. Regular concrete sand were replaced by foundry sand partially or fully. Concrete with a mix design of 1:1.5:3 was used and water/cement ratio of 0.55 or 0.45 was maintained. The results showed that regular concrete sand could be replaced by chemically bound foundry sand fully without adversely affecting the durability properties. Since the usually recommended usage of foundry sand in concrete is $30 \%$, it must be reviewed for different cases in-order to maximize the economical and environmental benefits.

Yogesh Aggarwal, and Rafat Siddique studied the performance of concrete with waste foundry sand and bottom ash in equal quantities as replacement of fine aggregates in various percentages (0-60\%). Concrete properties such as mechanical and durability characteristics along with micro structural analysis were investigated.

Replacing fine aggregate with waste foundry sand and bottom ash does not affect the strength properties adversely as the strength stays within limits except for $60 \%$ replacement. From the study, it was observed that, by substituting $30 \%$ of industrial by-product as natural fine aggregate, increase in compressive strength, split tensile strength and flexural strength was achieved. Also, the maximum \% of replacement was observed as $50 \%$.

Rafat Siddique et al carried out the comparative performance of two control concrete mixtures (M20 \& M30) by measuring compressive strength, split tensile strength, chloride permeability, modulus of elasticity and ultra pulse velocity tests. Spent foundry sand (SFS) is used as partial replacement for fine aggregate in different percentages $(0 \%, 5 \%, 10 \%, 15 \%$ and $20 \%)$ of SFS by weight. The tests were carried up to the age of 365days. Replacement of sand up to $15 \%$ of SFS increases strength properties of both grades (M20\&M30) of concrete, but influence of SFS is more prominent on M20 grade of concrete.

Ravinder Kaur Sandhu, and Rafat Siddique studied the influence of waste foundry sand (WFS) as a fine aggregate in self-compacting concrete (SCC). River sand was replaced with different percentages $(5,10,15,20,25$ and 30\%) of WFS by volume. Fresh state properties of SCC such as slump flow, $\mathrm{T}_{500}, \mathrm{~V}$-funnel-box and U-box tests were evaluated. Experimental investigations on strength and microstructural properties were carried up to the age of 365 days. The present study result shows that WFS can be effectively used up to $30 \%$ replacement of fine aggregate for the production of SCC. The utilization of WFS will develop economical and sustainable concrete.

Gurpreet Singh, and Rafat Siddique replaced natural sand in different ratios such as $(0 \%, 5 \%, 10 \%, 15 \%$ and $20 \%)$ of WFS by weight. Strength and durability properties such as compression strength, splitting tensile strength, modulus of elasticity and ultrasonic pulse velocity tests were conducted at the age of 7, 28, and 91 days. Strength properties of concrete increases with WFS up to $15 \%$ replacement of sand. Test result indicates that WFS can be effectively used in making structural grade concrete.

\section{CONCLUSION}

From the literature review, waste foundry sand satisfies all the desirable properties of river sand. The overview of those studies gives the optimum utilization of waste foundry sand in the 
range of $20 \%$ to $40 \%$. Thus, utilizing foundry sand in concrete overcomes the disposal issues and helps in reducing the cost of concrete.

\section{REFERENCES}

1. G. Ganesh Prabhu, Jung Hwan Hyun, and Yun Yong Kim, "Effects of foundry sand as a fine aggregate in concrete production," Construction and Building Materials, vol. 70, pp. 514-521, 2014.

2. Gurpreet Singh, and Rafat Siddique, "Abrasion resistance and strength properties of concrete containing waste foundry sand (WFS)," Construction and Building Materials, vol. 28, pp. 421426, 2012.

3. Thiruvenkitam Manoharan, Dhamothiran Laksmanan, Kaliyannan Mylsamy, Pandian Sivakumar, and Anirbid Sircar, "Engineering properties of concrete with partial utilization of used foundry sand," Waste Management, vol. 71, pp. 454-460, 2018.

4. Rafat Siddique, Yogesh Aggarwal, Paratibha Aggarwal, El-Hadj Kadri, and Rachid Bennacer, "Strength, durability, and micro-structural properties of concrete made with used-foundry sand (UFS)," Construction and Building Materials, vol. 25, pp. 1916-1925, 2011.

5. K. Sarumathi, S. Elavenil, and A.S. Vinoth, "Use of waste foundry sand with multiscale modeling in concrete," Asian Journal of Civil Engineering, vol.20, issue 2, pp. 163-170, 2018.

6. Gustavo J.L. Coppio, Maryangela Geimba de Lima, Julia W. Lencioni, Luciana S. Cividanes, Paulo P.O.L. Dyer, and Silvelene A. Silva, "Surface electrical resistivity and compressive strength of concrete with the use of waste foundry sand as aggregate," Construction and Building Materials, vol. 212, pp. 514-521, 2019

7. Yucel Guney, Yasin Dursun Sari, Muhsin Yalcin, Ahmet Tuncan, and Senayi Donmez, "Reusage of waste foundry sand in high-strength concrete," Waste Management, vol. 30, pp. 1705-1713, 2010.

8. Maria Mavroulidou, and David Lawrence, "Can waste foundry sand fully replace structural concrete sand?" Journal of Material Cycles and Waste Management, vol.21, pp.594-605, 2019.

9. Yogesh Aggarwal, and Rafat Siddique, "Microstructure and properties of concrete using bottom ash and waste foundry sand as partial replacement of fine aggregates," Construction and Building Materials, vol. 54, pp. 210-223, 2014.

10. Rafat Siddique, Gurpreet Singh, Rafik Belarbi, Karim Ait-Mokhtar, and Kunal, "Comparative investigation on the influence of spent foundry sand as partial replacement of fine aggregates on the properties of two grades of concrete," Construction and Building Materials, vol. 83, pp. 216-222, 2015.

11. Ravinder Kaur Sandhu, and Rafat Siddique, "Strength properties and microstructural analysis of self-compacting concrete incorporating waste foundry sand," Construction and Building Materials, vol. 225, pp. 371-383, 2019.

12. Gurpreet Singh, and Rafat Siddique, "Effect of waste foundry sand (WFS) as partial replacement of sand on the strength, ultrasonic pulse velocity and permeability of concrete," Construction and Building Materials, vol. 26, pp. 416-422, 2012. 